\title{
Prescription pattern of antihypertensive medications and blood pressure control among hypertensive outpatients at the University of Benin Teaching Hospital in Benin City, Nigeria
} Oluseyi Adejumo ${ }^{1}$, Enajite Okaka², Ikponmwosa Iyawe ${ }^{2}$

1. Kidney Care Centre, University of Medical Sciences, Ondo, Nigeria

2. Department of Internal Medicine, University of Benin Teaching Hospital, Benin City, Nigeria

Correspondence: Dr Oluseyi Adejumo (ceeward2010@yahoo.com)

\section{Background}

Abstract

The prevalence of hypertension and attendant cardiovascular disease burden is increasing globally. Auditing antihypertensive prescriptions and assessing patients with hypertension for blood pressure (BP) control are important steps on the path to reducing hypertensionrelated morbidity, mortality, and health expenditure. This study assessed the prescription pattern of antihypertensive medications and BP control among hypertensive outpatients at the University of Benin Teaching Hospital in Benin City, Nigeria.

Methods

This was a cross-sectional descriptive study that involved 224 hypertensive patients. Information obtained from participants included sociodemographic data, duration of hypertension, history of diabetes mellitus, and number and classes of antihypertensive medications used. Good BP control was defined as a mean BP less than $140 / 90 \mathrm{mmHg}$.

Results

The mean age of hypertensive subjects was $59.6 \pm 12.2$ years, with a male:female ratio of 1:1.9 and a median duration of hypertension of 5 years. Twenty-four participants $(10.7 \%)$ had both hypertension and diabetes. The common classes of antihypertensive medications used were diuretics, calcium channel blockers (CCB), and angiotensin converting enzyme inhibitors (ACEIs). Forty participants (17.8\%) were on monotherapy, while the rest were on multidrug therapy. The most commonly prescribed antihypertensive combination was diuretic + ACEI/angiotensin receptor blocker (ARB), followed by diuretic + CCB + ACEI/ARB.

Good BP control was observed in 120 participants (53.6\%). The proportion of patients with good BP control was largest among patients on monotherapy and those with tertiary education, though these observations were not statistically significant.

Conclusions

The pattern of prescribed antihypertensive medications complied with recommended guidelines. Blood pressure control amongst hypertensive patients was unsatisfactory. More efforts should be geared towards better BP control.

\section{Introduction}

Hypertension is an important public health problem worldwide and a major contributing factor to the development of noncommunicable diseases, especiallly cardiovascular disease. ${ }^{1,2}$ Noncommunicable diseases were estimated by the World Health Organization (WHO) to account for 38 million out of an estimated 56 million deaths in 2012; with cardiovascular disease accounting for $46.2 \%$ of deaths. ${ }^{3}$ The number of deaths from noncommunicable disease is projected to increase to 52 million by the year 2030, with cardiovascular disease being a major contributor. ${ }^{4}$

The burden of cardiovascular disease, specifically, is also on the increase, especially in developing countries. In Nigeria, the pooled prevalence of hypertension has increased significantly in the last four decades, from $8.9 \%$ to $22.5 \% .^{5}$

Hypertension-related diseases accounted for between $20.5 \%$ and $69.6 \%$ of the total admitted medical cases in various studies across Nigeria, with a high case fatality rate of up to $42.9 \%$. $^{6-8}$

Hypertension is a major risk factor for chronic kidney disease, coronary artery disease, stroke, arrhythmias and retinopathy. ${ }^{9-12}$ In the United States, it has been reported that the indirect expenses attributable to inadequate BP control amount to about 1.4 billion US dollars per year. ${ }^{13}$ Despite these facts, reports from both developed and developing countries have shown that BP control is still unsatisfactory among patients with hypertension. ${ }^{14-18}$

Effective treatment of hypertension has been reported to reduce the risk of stroke, coronary heart disease, congestive cardiac failure, and overall mortality. ${ }^{19}$ Efforts should therefore be intensified towards achieving BP control using recommended guidelines in order to reduce hypertensionrelated morbidity, mortality, and healthcare expenditure. Auditing antihypertensive prescription patterns and assessing individuals with hypertension for blood pressure (BP) control can play key roles in the efforts to mitigate the burden of hypertension.

The aim of this study was to audit the prescription pattern of antihypertensive medications and assess BP control among patients with hypertension attending a medical outpatient clinic at the University of Benin Teaching Hospital, Benin City, Edo State, Nigeria.

\section{Methods}

\section{Study setting}

This study was carried out at the Medical Outpatient Department of the University of Benin Teaching Hospital in Benin City, Edo State, which is a tertiary hospital in southern Nigeria, over a period of 8 weeks from 1st December 2012 
to 31st January 2013. This hospital receives referrals from hospitals within and outside Edo state. The clinic is open to patients twice weekly, and an average of 15 new hypertensive patients are seen weekly.

\section{Sample size}

The sample size was derived using the Kish Leslie equation for descriptive studies, as follows ${ }^{20}$ :

$\mathrm{N}=\frac{\mathrm{Z}^{2} \mathrm{pq}}{\mathrm{d}^{2}} \quad$ where,

$\mathrm{Z}$ is set at 1.96, which corresponds to the 95 percent confidence interval;

$\mathrm{P}=$ the proportion of the study population estimated to have hypertension from a previous study, which was $14.5 \% 0^{21}$; $\mathrm{q}=1.0-\mathrm{P}$; and

$\mathrm{d}=$ degree of accuracy desired, usually set at 0.05 .

$\frac{\mathrm{Z}^{2} \mathrm{pq}}{\mathrm{d}^{2}}=\frac{(1.96)^{2 * 0.145 *(1-1.045)}}{(0.05)^{2}}=191$

This formula gave a minimum sample size of 191, and 224 participants were subsequently recruited during the study period. Convenience sampling was used-consecutive eligible and consenting patients with hypertension were recruited. Inclusion criteria were as follows: age above 18 years and registration with the hypertension follow-up clinic for at least 3 months. Patients with acute heart failure, cardiomyopathy, or valvular heart disease were excluded.

\section{Data collection}

Participants were interviewed with the guidance of a form that requested the following information: age, gender, educational status, duration of hypertension, and history of diabetes mellitus. Information about antihypertensive medication, including specific drugs and doses, were obtained from the clinic's patient files.

Participant BPs were measured in a sitting position, after 5 minutes of rest, on the right arm, and using a mercury sphygmomanometer that was placed at the level of the heart. The systolic and diastolic pressures were read to the nearest $2 \mathrm{mmHg}$. Systolic BP and diastolic BP were taken at phase 1 and phase 5 Korotkoff sounds, respectively.

The mean of 3 consecutive BP readings taken at 5-minute interval was recorded. Good BP control was defined as a mean BP less than 140/90 $\mathrm{mmHg}^{22}$

\section{Data analysis}

Data were analysed using the Statistical Package for Social Sciences (SPSS), version 17.0. Means and standard deviations were calculated for normally distributed data, and medians and interquartile ranges for skewed data. Frequencies and percentages were calculated for discrete variables. The chi-square test was used to determine the significance of observed differences for categorical variables. P-values less than 0.05 were considered significant.

\section{Ethical considerations}

Ethical approval was obtained from the teaching hospital's ethical committee on research, and informed consent was obtained from all the study participants.
Table 1: Study sample characteristics $(\mathrm{N}=\mathbf{2 2 4})$

\begin{tabular}{|c|c|}
\hline Characteristic & n (\%) $\mid$ Mean \pm SD $\mid$ Median [IQR] \\
\hline Median duration of hypertension (years) & $5[7]$ \\
\hline Mean age (years) & $59.6 \pm 12.2$ \\
\hline \multicolumn{2}{|l|}{ Age groups } \\
\hline$<40$ years & $13(5.8)$ \\
\hline 41-49 years & $94(41.7)$ \\
\hline$\geq 60$ years & $117(52.5)$ \\
\hline \multicolumn{2}{|l|}{ Gender } \\
\hline Male & $76(33.9)$ \\
\hline Female & $148(66.1)$ \\
\hline \multicolumn{2}{|l|}{ Level of education } \\
\hline No formal education & $38(17.0)$ \\
\hline Primary & $68(30.3)$ \\
\hline Secondary & $41(18.3)$ \\
\hline Tertiary & $77(34.4)$ \\
\hline \multicolumn{2}{|l|}{ Antihypertensive medications } \\
\hline Median number of drugs & $2[1]$ \\
\hline Diuretics & $145(64.7)$ \\
\hline Calcium channel blockers & $123(54.9)$ \\
\hline Angiotensin converting enzyme inhibitors & $100(44.6)$ \\
\hline Angiotensin receptor blockers & $62(27.7)$ \\
\hline Beta blockers & $46(20.5)$ \\
\hline Alpha-2 agonist, centrally acting & $21(9.4)$ \\
\hline Alpha blockers & $7(3.1)$ \\
\hline Fixed-drug combinations & $115(51.8)$ \\
\hline Individual pills & $108(48.2)$ \\
\hline Monotherapy & $40(17.8)$ \\
\hline 2 drugs & $111(49.6)$ \\
\hline$\geq 3$ drugs & $73(32.6)$ \\
\hline \multicolumn{2}{|l|}{ Blood pressure control } \\
\hline Good & $120(53.6)$ \\
\hline Poor & $104(46.4)$ \\
\hline
\end{tabular}

\section{Results}

A total of 224 patients were seen during the study collection period. There were 76 male participants (33.9\%) and 148 females $(66.1 \%)$. The median duration of hypertension was 5 years. Mean age was $59.6 \pm 12.2$ years, with about half of the study participants being $\geq 60$ years of age. Thirtyseven patients $(17 \%)$ did not have formal education, while 77 (34.4\%) attained tertiary-level education. Twenty-four participants $(10.7 \%)$ had both hypertension and diabetes.

The most commonly prescribed antihypertensive medications were diuretics for 145 patients (64.7\%), calcium channel blockers (CCBs) for 123 patients (54.9\%), and angiotensin converting enzyme inhibitors (ACEIs) for 100 patients (44.6\%). Alpha-1 blockers and centrally acting alpha-2 agonists were the least commonly prescribed classes. One hundred and fifteen participants $(51.8 \%)$ were on fixeddose combinations (Table 1).

The common BP drug combinations used by patients were diuretic + ACEI/angiotensin receptor blocker (ARB) for 43 patients $(19.2 \%)$, diuretics + CCB + ACEI or ARB for 33 patients (14.7\%), CCB + ACEI or ARB in $25(11.2 \%)$ and $\mathrm{CCB}+$ diuretic in 22 patients $(9.8 \%)$. (Figure 1$)$. 


\section{Figure 1: Prescribed antihypertensive drug combinations}

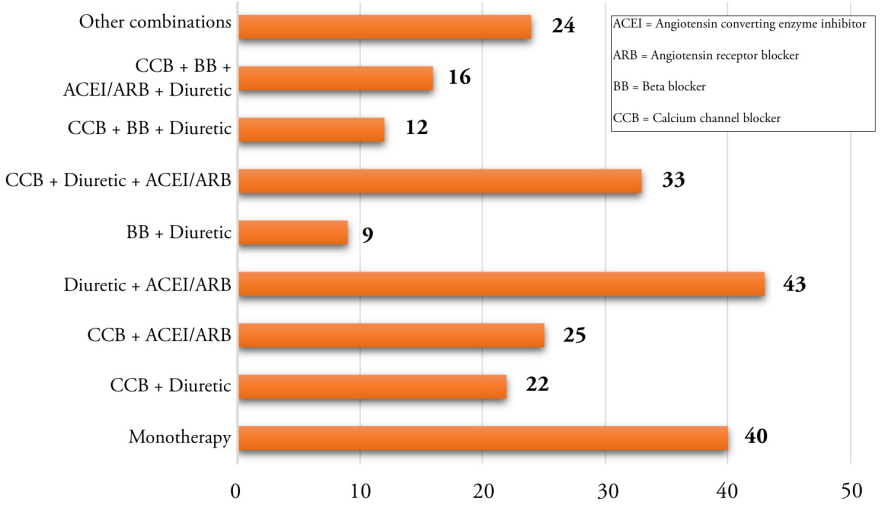

Figure 2: Good blood pressure control versus number of prescribed antihypertensive drugs

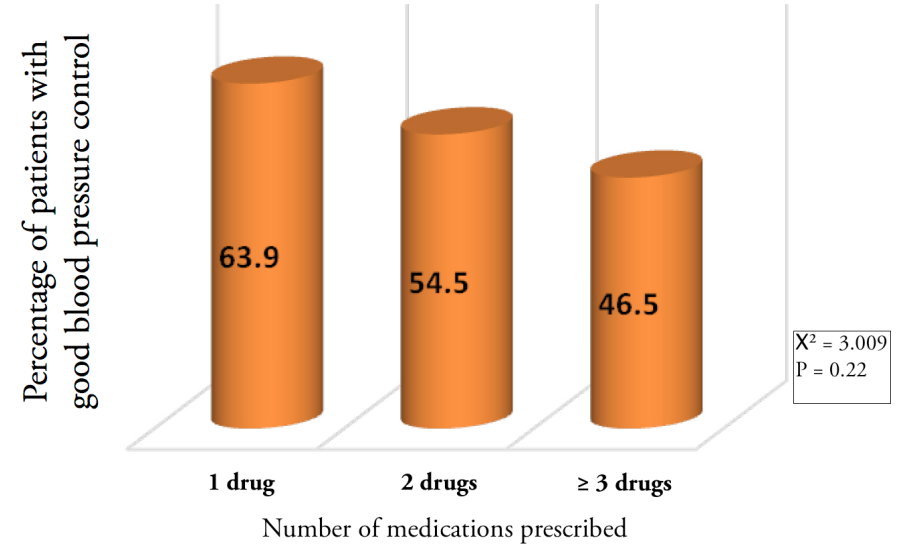

Figure 3: Good blood pressure control versus patient educational level

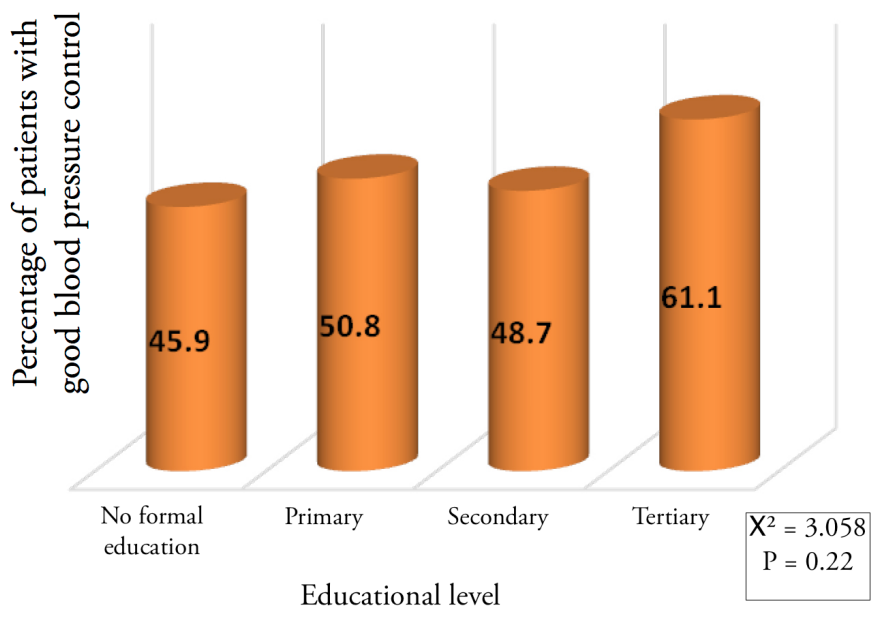

Blood pressure control was good in 120 (53.6\%) of the study subjects. One hundred and eleven patients (49.6\%) were on 2 BP medications, while $40(17.8 \%)$ were on 1 BP medication and $73(32.6 \%)$ of the patients were on 3 or more BP medications.

The proportion of patients with good BP control was largest $(63.9 \%)$ among patients on $1 \mathrm{BP}$ medication and lowest $(46.5 \%)$ among patients on 3 or more BP medications (Figure 2). This finding, however, was not statistically significant $\left(\mathrm{X}^{2}=0.3009, \mathrm{P}=0.222\right)$. Good BP control was observed in $58(51.3 \%)$ of the patients on fixed-drug combinations, while $59(55.7 \%)$ of the patients taking individual pills had good BP control. Again, this difference was not statistically significant.
In terms of education, the proportion of patients with good $\mathrm{BP}$ control was largest among patients with tertiary education and lowest among patients without formal education, but this observation was not statistically significant (Figure 3).

\section{Discussion}

Unsurprisingly, the majority of the hypertensive patients in this study were above 40 years of age; this finding is comparable to previous reports related to hypertension among Nigerians. ${ }^{16,23}$ Hypertension is more prevalent among older individuals due to increased arterial and arteriolar wall stiffness, decreased baroreceptor sensitivity, increased responsiveness to sympathetic nervous stimuli, and altered renal and sodium metabolism associated with aging. ${ }^{24,25}$

Although the prevalence of hypertension among Nigerians has been reported to be similar in men and women, ${ }^{5}$ this study sample consisted of more females, which is similar to some previous reports. ${ }^{23,26}$ The female gender predominance in this study may reflect better health-seeking behaviour by women compared to men, as reported elsewhere. ${ }^{27}$

Most of the hypertensive subjects were on multidrug therapy, with less than $20 \%$ on monotherapy, which was comparable to findings in a previous report from Nigeria. ${ }^{28}$ The most commonly prescribed antihypertensive medications in this study were thiazide diuretics, CCBs and ACEIs-again similar to previous reports from Nigeria. ${ }^{16,23,28}$ It is not surprising that thiazides were the most frequently used hypertensive drugs, since hypertension in blacks is known to commonly be volume dependent and responsive to these medications. Thiazides are also relatively inexpensive when compared with other classes of antihypertensive medication. The most common antihypertensive drug combinations were diuretics + ACE or ARBs and diuretics + CCBs + ACEIs or ARBs. This pattern of antihypertensive medication use showed compliance with the Eight Joint National Committee Guidelines on Prevention, Detection, Evaluation and Treatment of High Blood Pressure (JNC 8). ${ }^{22}$ The pattern of antihypertensive drug prescription in this study also suggested an improvement in medical practice compared to what was reported 5 years ago after a study conducted in Benin City, where CCBs were the most prescribed class of drug. ${ }^{26}$ Alpha-1 blockers and centrally acting alpha-2 agonists were the least prescribed antihypertensive medications in this study, which is similar to earlier reports. ${ }^{23}$

The proportion of patients with good BP control was $53.6 \%$ in this study. Previous studies in both developing and developed countries have shown good BP control rates between $33 \%$ and $70.7 \% .^{14-18,28-29}$ Factors that account for this variation include differences in criteria used to define good BP control, medication adherence, accessibility to free antihypertensive medications, and differences in education provision and counselling by health workers. ${ }^{14,15,16,28}$

Good BP control was higher in this study compared to previous reports from 2 different tertiary hospitals in northern Nigeria, most likely predominantly owing to the stricter BP cut-off of $<130 / 80 \mathrm{mmHg}$ in defining good BP control among patients with both hypertension and diabetes in these studies. ${ }^{14,15}$ Also, regular pre-clinic counselling, given by nurses, to attendees of the hypertension clinic at our hospital may have contributed to better BP control in our patients. The BP cut-off value of $140 / 90 \mathrm{mmHg}$ was used to define good BP control in this study (including patients with diabetes), as recommended by JNC 8. The 
proportion of subjects with good BP control in this study was similar to that found in previous studies that used similar criteria. ${ }^{16,17,29,30}$

Good BP control was best in patients with tertiary education and worst in those who did not have any form of formal education. This could be because educated patients are more equipped to appreciate the implications of poor adherence to treatment. Also, patients with a higher educational levels tend to be wealthier and more able to afford their medications, compared to those without formal education. Previous research has shown that both educational and socioeconomic status can be important factors in the management and outcome of hypertension. ${ }^{28}$

The proportion of patients with good control was highest among those on monotherapy. Good BP control is usually more easily achieved with a single drug for patients with mild hypertension than for patients with moderate to severe hypertension, who often require multidrug therapy. Additionally, the pill burden with single therapy is far less tasking compared with multidrug therapy, and this facilitates better compliance and BP control among individuals on single therapy with mild hypertension. However, this observation should be interpreted with caution because less than $20 \%$ of the study subjects were on monotherapy. It is noteworty that other research carried out in Nigeria has found that subjects on multitherapy had better BP control. ${ }^{16,23}$

Frequency of clinic attendance, medication adherence, and other factors that may affect BP (such as lifestyle modification) were not assessed in this study. Also, clusters of cardiovascular risk factors and severity of hypertension at commencement of treatment, which could affect BP control, were not included in this study. These limitations are important to consider when interpreting these results; nonetheless, simple and inexpensive audits such as this one can provide health systems and individual facilities with benchmarks for monitoring and evaluating progress on a significant and growing public health concern in Africa.

\section{Conclusions}

Although the proportion of patients with good BP control in this study was higher than some previous reports, the level of BP control among hypertensive patients was still unsatisfactory. Even though the prescription pattern of antihypertensive medications in the study centre complied with recommended guidelines, efforts geared towards BP control should be intensified, in order to reduce associated morbidity, mortality, and expenditure.

\section{Competing interests}

All authors declare that they have no competing interests related to this work.

\section{References}

1. Wolf-Maier K, Cooper RS, Banegas JR, Giampaoli S, Hense HW, Joffres $\mathrm{M}$ et al. Hypertension prevalence and blood pressure levels in 6 European countries, Canada, and the United States. JAMA 2003;289:2363-2369.

2. Muna WF. Cardiovascular disorders in Africa. World Health Stat Q 1993;46:125-133

3. World Health Organization. Projections of mortality and causes of death, 2015 and 2030 (http://www.who.int/healthinfo/global_burden_ disease/projections/en)

4. Mathers CD, Loncar D. Projections of global mortality and burden of disease 2002-2030. PLoS Med. 2006;3(11): e442. Doi:10.1371/journal. pmed.0030442

http://dx.doi.org/10.4314/mmj.v29i2.7
5. Ogah OS, Okpechi I, Chukwuonye II, Akinyemi JO, Onwubere $\mathrm{BJC}$, Falase $\mathrm{AO}$ et al Blood pressure, prevalence of hypertension and hypertension related complications in Nigerian Africans: A review. World J Cardiol. 2012; 4(12): 327-340

6. Kolo PM, Jibrin YB, Sanya EO, Alkali M, Peter Kio IB, Moronkola RK. Hypertension related admissions and outcome in a tertiary hospital in Northeast Nigeria. Int J Hyper Volume 2012, Article ID 960546. http:dx.doi.org/10.1155/2012/960546

7. Ike SO. Prevalence of hypertension and its complications among medical admissions at the University of Nigeria Teaching Hospital, Enugu(Study 2).Niger J Med 2009;18(1):68-72

8. Arodiwe FB, Ike SO,Nwokediuko SC. Case fatality of hypertension related admission in Enugu, Nigeria. Niger J Clin Prac 2009;12(2):153156

9. Arogundade FA, Sanusi AA, Hassan MO, Akinsola A. The pattern, clinical characteristics and outcome of ESRD in Ile-Ife, Nigeria: is there a change in trend? Afr Health Sci. 2011;11:594-601

10. Okeahialam BN. The burden of arrhythmia in hypertension: an electrocardiographic study. Nig J Cardiol.2004;1:53-56

11. Oluleye TS, Ajaiyeoba AI. Retinal diseases in Ibadan. Eye 2006;20: 1461-1463.

12. Komolafe MA, Ogunlade O, Komolafe ED. Stroke mortality in a teaching hospital in south-west of Nigeria. AJNS 2006;25(2):75-77

13. Flack JM, Casciano R,Casciano J, Doyle J, Arikian S, Tang S, Arocho R. Cardiovascular disease costs associated with uncontrolled hypertension. Managed Care Interface 2002;15:28-36

14. Sani MU, Mijinyawa MS, Adamu B, Abdu A, Borodo MM. Blood pressure control among treated hypertensive in a tertiary health institution. Niger J Med 2008;17(3):270-274

15. Gimba ZM, Akinbuwa BA, Agaba PA,Abere EE, Agaba EI. Audit of anti-hypertensive medication prescription in Nigeria: a comparison of two tertiary hospital. High Med Res J 2013;13(2):1-5

16. Olanrewaju TO, Aderibigbe A, Chijioke A, Sanya EO, Busari OA, Kolo PI et al. Descriptive analysis of blod pressure control among treated hypertensive patients in a tertiary hospital in Nigeria. Afr J Med Med Sci 2011;40(3):207-212

17. Ordunez-Garcia P, Munoz JL, Pedraza D, Espinosa-Brito A, Silva LC, Cooper RS. Success in control of hypertension in a low-resource setting: the Cuban experience. J Hypertens 2006;24(5):845-849

18. TJ Wang, Vasan RS. Epidemiology of uncontrolled hypertension in the United States. Circulation 2005;112(11):1651-1662

19. Psaty BM, Lumley T, Furberg CD, Schellenbaum G, Pahor $\mathrm{M}$, Alderman $\mathrm{MH}$ et al. Health outcomes associated with various antihypertensive therapies used as first -line agents: a network metanalysis. JAMA 2003;289:2534-2544

20. Kish Leslie. Survey Sampling. New York:John Wiley and Sons, Inc 1965

21. Cooper R, Rotimi C, Ataman S, McGee D, Osotimehin B, Kadiri $\mathrm{S}$ et al. The prevalence of hypertension in seven population of West African origin. Am J. Public Health 1997;87(2):160-168

22. James PA, Oparil S, Carter BL, Cushman WC, DennisonHimmerlfarb $\mathrm{C}$ et al. 2014-Evidence based guideline for the management of high blood pressure in adults: report from the panel member appointed to the eight Joint national committee (JNC 8). JAMA 2014;311(5): 507-520

23. Busari OA, Oluyombo R, Fasae AJ, Gabriel EO, Ayodele LM, Agboola SM et al. Prescribing pattern and utilization of antihypertensive drugs and blood pressure control in adults patients with systemic hypertension in a rural tertiary hospital in Nigeria. Am J Inter Med 2014;2(6):144-149 
24. Pinto E. Blood pressure and aging. Postgrad Med J 2007;83(976): 109114

25. Weber MA, Neutel JM, Cheung DG. Hypertension in the aged: a pathophysiologic basis for treatment. Am J Cardiol 198963(16)25-32

26. Odili VU, Oghagbon EK, Ugwa NA, Ochei UM, Aghom OE. Adherence to treatment guidelines in management of hypertension in a tertiary hospital in Nigeria. Trop J Pharm Res 2008;7(2):945-952

27. Abdulraheem IS. Health needs assessment and determinants of health-seeking behavior among elderly Nigerians: A house-hold survey. Ann Afr Med 2007;6:58-63

28. Busari OA, Olanrewaju TO, Desalu OO, Opadijo GO, Jimoh AK, Agboola SM et al. Impact of knowledge, attitude and practices on hypertension on compliance with antihypertensive in a resource-poor setting. TAF Prev Med Bull 2010;9(2):87-92
29. Adedapo AD, Sikuade O, Adeleke S, Okechukwu R. Drug utilization and blood pressure control in a population where antihypertensives are given free: effect of policy change. Afr Med Med Sci 2012;41:349-356

30. Akunne OO, Adedapo ADA. Drug prescripton/ blood pressure control in patients on monotherapy attending a tertiary hospital in Nigeria . IJBCP 2014;3(6):983-987

31. Cuspidi C, Lonati L, Sampieri L, Macca G, Valagussa L,Zaro T et al. Blood pressure control in a hypertension hospital clinic. J Hypertens 1999;17(6):835-841. 